\title{
Clinical practice guidelines in the intensive care unit: a survey of Canadian clinicians' attitudes
}

\author{
[Guide de pratique clinique dans les unités de soins intensifs: un sondage sur les \\ attitudes des cliniciens canadiens]
}

\author{
Tasnim Sinuff MD PhD, ${ }^{*}$ Kevin W. Eva PhD, $†$ Maureen Meade MD MSc, $† \ddagger$ Peter Dodek MD MHSc, $\$$ \\ Daren Heyland MD MSc, I Deborah Cook MD Msc†‡
}

\begin{abstract}
Purpose: To understand clinicians' perceptions regarding practice guidelines in Canadian intensive care units (ICUs) to inform guideline development and implementation strategies.

Methods: We developed a self-administered survey instrument and assessed its clinical sensibility and reliability. The survey was mailed to ICU physicians and nurses in Canada to determine local ICU guideline development and use, and to compare physicians' and nurses' attitudes and preferences towards guidelines.
\end{abstract}

Results: The survey was completed by $51.6 \%$ (565/1095) of potential respondents. Although less than half reported a formal guideline development committee in their ICU, $81.0 \%$ reported that guidelines were developed at their institutions. Of clinicians who used guidelines in the ICU, $70.2 \%$ of nurses and $42.6 \%$ of physicians reported using them frequently or always. Professional society guidelines (with or without local modification) were reportedly used in most ICUs, but physicians were more confident than nurses of their validity $(P<$ 0.001 ). Physicians considered endorsement of guidelines by a colleague more relevant for enhancing guideline use than did nurses $(P<0.001)$. Nurses considered low risk of the guideline and whether the guideline is consistent with their practice $(P<$ $0.00 \mathrm{I})$ to be more relevant to guideline uptake than did physicians $(P<0.001)$. Lack of agreement with recommendations was a more important barrier to use of guidelines for physicians than for nurses $(P<0.001)$.

Conclusions: Many Canadian institutions locally develop guidelines, and many ICU physicians and nurses report using them.
Planning implementation strategies according to clinician preferences may increase guideline use. The nature of the differences in attitudes towards guidelines between nurses and physicians, and their impact on clinician adherence to guidelines requires further exploration.

CAN J ANESTH $2007 / 54: 9$ / pp 728-736

Objectif: Comprendre les perceptions des cliniciens quant aux guides de pratique dans les unités de soins intensifs afin d'améliorer le développement de directives et la mise en œuvre de stratégies.

Méthode : Nous avons développé un sondage auto-administré et avons évalué sa sensibilité et sa fiabilité cliniques. Le formulaire de sondage a été envoyé à des intensivistes et des infirmiers/infirmières au Canada afin de déterminer l'utilisation et le développement local de guides de pratique dans les unités de soins intensifs, et de comparer les attitudes et préférences des médecins et des infirmiers/infirmières quant aux guides de pratique.

Résultats : Le questionnaire a été rempli par 5I,6\% (565/I095) des répondants potentiels. Bien que moins de la moitié aient fait état d'un comité officiel de développement d'un guide de pratique dans leur unité de soins intensifs, 8I,0\% rapportent que certains guides ont été développés dans leur institution. Parmi les cliniciens utilisant des guides de pratique aux soins intensifs, $70,2 \%$ des infirmiers/infirmières et $42,6 \%$ des médecins ont répondu les utiliser fréquemment ou toujours. Les guides de pratique de socié-

From the Department of Critical Care \& Sunnybrook Research Institute, Sunnybrook Health Sciences Centre, \& Interdepartmental Division of Critical Care, ${ }^{*}$ University of Toronto, Toronto Ontario; the Department of Clinical Epidemiology \& Biostatistics, $†$ and Medicine, $\ddagger$ McMaster University, Hamilton, Ontario; the Department of Medicine \& Centre for Health Evaluation and Outcome Sciences, $\mathbb{S}$ University of British Columbia, Vancouver, British Columbia; and the Department of Medicine, $\mathbb{I}$ Queen’s University, Kingston, Ontario, Canada.

Address correspondence to: Dr. Tasnim Sinuff, Department of Critical Care Medicine, Sunnybrook Health Sciences Centre, Room D131, 2075 Bayview Avenue, Toronto, Ontario M4N 3M5, Canada. Phone: 416-480-6100, ext 7694; Fax: 416-480-4999; E-mail: taz. sinuff@sunnybrook.ca

This survey was supported by the Canadian Critical Care Society and the Canadian Association of Critical Care Nurses.

Sources of financial support: Hamilton Health Sciences New Investigator Fund. Dr Sinuff is supported by a Canadian Institutes for Health Research Clinician Scientist Award. Dr Cook is a Research Chair of the Canadian Institutes for Health Research.

Financial disclosure: No author has a financial relationship with a commercial entity that has an interest in the subject of this manuscript. Accepted for publication April 22, 2007.

Revision accepted June 25, 2007. 
tés professionnelles (avec ou sans modification locale) sont, selon le sondage, utilisés dans la plupart des unités de soins intensifs, mais les médecins ont montré plus de confiance dans leur validité que les infirmiers/infirmières $(P<0,001)$. Les médecins ont considéré la reconnaissance du guide de pratique par un collègue comme plus influente vis-à-vis de l'observance d'un guide de pratique que les infirmiers/infirmières $(P<0,00 I)$. Les infirmiers/infirmières ont considéré qu'un guide de pratique au risque réduit et sa cohérence avec la pratique quotidienne $(P<0,00 I)$ étaient plus pertinents à l'adoption d'un guide de pratique que les médecins $(P<0,00 I)$. Le désaccord concernant les recommandations a constitué une barrière plus importante à la mise en pratique d'un guide pour les médecins que pour les infirmiers/infirmières $(P<0,00 I)$.

Conclusion: De nombreuses institutions canadiennes développent des guides de pratique localement, et de nombreux médecins et infirmiers/infirmières des soins intensifs rapportent leur utilisation. La planification de stratégies de mise en œuvre selon les préférences des cliniciens pourrait accroître l'utilisation des directives. La nature des différences quant aux guides par les infirmiers/infirmières et les médecins, ainsi que leur impact sur l'observance en clinique des guides, nécessitent des études approfondies.

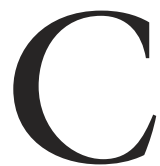

RITICAL care professional societies have developed clinical practice guidelines for acutely and critically ill hospitalized patients. Great personnel and financial resources are required to develop guidelines. Disappointingly, observational studies ${ }^{1-7}$ and randomized controlled trials $^{8}$ conducted within the intensive care unit (ICU) have generally shown no clear benefit from the use of guidelines as measured by improvements in processes and outcomes of patient care. High quality professional society practice guidelines such as the recent guidelines for the prevention of ventilator associated pneumonia jointly developed by the Canadian Critical Care Society (CCCS) and the Canadian Critical Care Trials Group 9 may have had a different effect, but this has not been measured. Nevertheless, it is now understood that the successful implementation of guidelines into critical care practice is influenced by the attitudes of end-users towards the guidelines.

Self-administered surveys of Canadian ${ }^{10}$ and American ${ }^{11,12}$ internists have found that familiarity with guidelines varies depending upon guideline type; subspecialists are more familiar with guidelines developed by their specialty organizations. ${ }^{10-12}$ Some clinicians believe that guidelines are an oversimplified approach to medicine, are too rigid to apply to individual patients, and challenge physician autonomy. ${ }^{10-12} \mathrm{~A}$ recent systematic review found that many physicians perceive guidelines as difficult to use and confusing, and that guideline format is often a major barrier to use. ${ }^{13}$
The foregoing data may not apply in the ICU setting. The nature of critical illness, the multidisciplinary team approach to care, and use of advanced life support technology may result in different attitudes and preferences regarding guidelines. Each ICU has a unique mix of practice patterns, which may influence clinicians' acceptability of guidelines, their attitudes towards the utility of guidelines, and their behaviours regarding guideline use. Because physicians and nurses are both integral to the ICU team, and their perceptions may differ, ${ }^{14}$ understanding both clinician groups' attitudes and preferences regarding guidelines is an important step in developing effective ICU guidelines. This knowledge may help overcome barriers to guideline implementation. ${ }^{13}$ Our objective was to determine attitudes and preferences regarding practice guidelines for the care of critically ill patients, to ascertain interprofessional differences, and to identify perceived determinants of guideline use in the ICU, among Canadian ICU physicians and nurses.

\section{Methods}

We conducted a detailed search of electronic databases and found no research addressing clinicians' attitudes or preferences regarding guidelines in the ICU. To generate items, we identified an initial set of domains of interest [clinician factors (demographics, attitudes, preferences), guideline factors (qualities, development, implementation, impact on clinical practice), ICU organizational factors], based on our review of the general medical literature ${ }^{10-12}$ and drew on our group's prior qualitative research. ${ }^{14,15}$

A team of five intensivists with expertise in health research methodology and practice guidelines developed questions within each domain. We defined practice guideline, protocols, clinical pathways, and algorithms and indicated that a practice guideline could incorporate these latter three terms (Table I). We asked respondents to consider only guidelines used to care for critically ill patients. However, we did not specify the topic or type of guideline (e.g., locally developed or professional society; prevention, diagnostic, or treatment) since we wanted respondents to consider guidelines in general.

Questions about guideline type and stated guideline use were formatted as binary responses (yes/no). Questions about attitudes towards guidelines were formatted using an adjectival scale, with a five-item response scale. We limited items to minimize redundancy and completion time, and maximize feasibility. To assess comprehensiveness and clarity, the potential range of responses achievable, and item redundancy we conducted interviews with five intensivists and five ICU nurses. 
TABLE I Definitions used for survey

\begin{tabular}{ll}
\hline Practice guideline & $\begin{array}{l}\text { A systematically developed statement } \\
\text { integrating the best current evidence and } \\
\text { clinical experience to assist clinicians in the } \\
\text { care of patients for specific clinical } \\
\text { circumstances. }\end{array}$ \\
A set of sequential steps developed to \\
standardize patient care regarding issues such \\
as diagnosis and treatment.
\end{tabular}

We asked a different group of five intensivists and five ICU nurses to assess the instrument's clarity, face validity, and comprehensiveness. Questions also addressed the time required to complete the survey, the appropriateness of the survey's length, and it's relevance to current clinical practice and future guideline research.

To examine individual-item, total-instrument, and test-retest reliability, we administered the questionnaire to 11 intensivists and 11 ICU research nurses in Canada two weeks apart. We calculated Cohen's kappa ( $\kappa)$ for each item as a measure of test-retest reliability. ${ }^{16}$ We established a priori criteria for item reduction based on $\kappa$ values. For test-retest reliability, a priori we considered $\kappa \geq 0.40$ to represent moderate to good agreement.

We mailed this survey (available as Additional Material at www.cja-jca.org) to ICU physicians (members of the CCCS) and ICU nurses (members of the Canadian Association of Critical Care Nurses (CACCN)). Non-responders were sent up to two additional surveys, each eight weeks apart. Survey completion was voluntary; all responses were anonymously coded. The study was approved by the Research Ethics Board of McMaster University (Hamilton, Ontario).

\section{Analysis}

All survey questions were analyzed. We present descriptive statistics as proportions, percentages, and means \pm SD and $95 \%$ confidence intervals. Differences in responses between physicians and nurses were determined using a t test of the difference between means for questions with responses framed on a con-

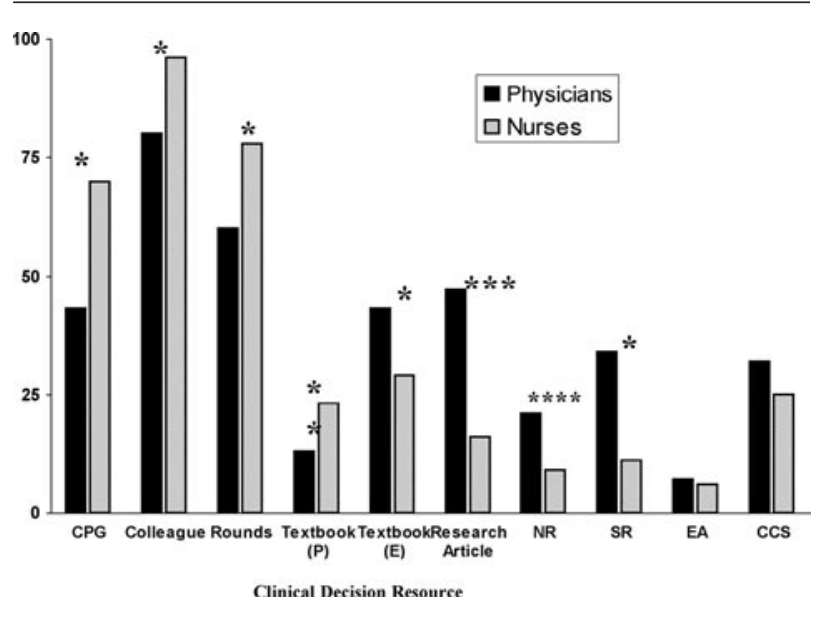

FIGURE Informational resources used by intensive care unit (ICU) physicians and nurses frequently or always to aid clinical decision-making in the ICU. CPG = clinical practice guideline; colleague $=$ discussion with colleagues or consultants; rounds = multidisciplinary rounds; Textbook $(\mathrm{P})=$ paper formatted textbook; Textbook $(\mathrm{E})=$ electronically formatted textbook; NR = narrative review; $\mathrm{SR}=$ systematic review; $\mathrm{EA}=$ economic analysis; $\mathrm{CCS}=$ consensus conference statement. ${ }^{*} P<0.001 ;{ }^{*} P=0.02$;

${ }^{* *} P=0.006 ; * * * P=0.001$.

tinuous scale. All $P$-values are two-sided; $P \leq 0.05$ was considered statistically significant. Two linear regression analyses were conducted to determine factors related to physicians' and nurses' stated use of guidelines ( scale of $\mathrm{l}=$ never use to $5=$ always use treated as a continuous dependent variable). We selected independent variables based on a priori hypotheses and within acceptable limits of the respondent sample size (Appendix). Variables significant at $P \leq 0.1$ in the univariable analysis were entered into the multivariable model, using backward elimination. ${ }^{17}$ Variables were considered statistically significant in the multivariable analysis if $P \leq 0.05$. We assessed model fit $\left(\mathrm{R}^{2}\right)^{17}$ and developed main effects models only. Data were analyzed using SAS software, version 8 (SAS Institute, Cary, NC, USA).

\section{Results}

The survey completion rate was $51.6 \%(565 / 1095)$ for active members of the CCCS and CACCN working in an ICU; $54.7 \%(123 / 225)$ of intensivists and $50.8 \%$ $(442 / 870)$ of nurses completed surveys. Of those who responded, $63.2 \%(384 / 551)$ had an academic affiliation $[85.0 \%(102 / 120)$ of physicians, $57.1 \%(246 / 431)$ 
TABLE II Comparison of ICU physicians' and nurses' opinions about practice guidelines

\begin{tabular}{|c|c|c|c|}
\hline & $\begin{array}{l}\text { Physicians mean } \\
(95 \% \text { CI })\end{array}$ & $\begin{array}{l}\text { Nurses mean } \\
(95 \% \text { CI })\end{array}$ & $\begin{array}{l}\text { P-value for } \\
\text { mean difference }\end{array}$ \\
\hline Good educational tools & $3.96(3.81,4.10)$ & $4.30(4.23,4.37)$ & $<0.001$ \\
\hline Development motivated by desire to cut costs & $3.40(3.23,3.56)$ & $3.31(3.21,3.42)$ & 0.393 \\
\hline Convenient source of advice & $3.90(3.76,4.04)$ & $3.98(3.90,4.06)$ & 0.372 \\
\hline Summary of research evidence & $4.17(4.05,4.28)$ & $4.09(4.01,4.17)$ & 0.294 \\
\hline Too rigid to apply to individual patients & $2.45(2.25,2.64)$ & $2.31(2.22,2.40)$ & 0.172 \\
\hline Challenge to clinician autonomy & $2.14(1.95,2.33)$ & $2.37(2.27,2.47)$ & 0.033 \\
\hline If not followed, guidelines may be used for disciplinary action & $2.05(1.86,2.24)$ & $2.55(2.44,2.65)$ & $<0.001$ \\
\hline
\end{tabular}

Responses were framed on a continuous scale from 1 = strongly disagree to $5=$ strongly agree for each question, where 3 is neutral. ICU = intensive care unit; $\mathrm{CI}=$ confidence interval.

TABLE III Stated guideline formatting and presentation preferences

\begin{tabular}{|c|c|c|c|}
\hline & $\begin{array}{l}\text { Physicians mean } \\
(95 \% \mathrm{CI})\end{array}$ & $\begin{array}{l}\text { Nurses mean } \\
(95 \% \mathrm{CI})\end{array}$ & $\begin{array}{l}\text { P-value for } \\
\text { mean difference }\end{array}$ \\
\hline \multicolumn{4}{|l|}{ Paper formats } \\
\hline Manual & $3.08(2.91,3.25)$ & $4.00(3.91,4.08)$ & $<0.001$ \\
\hline Pocket card & $3.43(3.28,3.58)$ & $3.86(3.76,3.95)$ & $<0.001$ \\
\hline Poster & $3.21(3.04,3.38)$ & $3.80(3.72,3.88)$ & $<0.001$ \\
\hline Journal article & $3.64(3.49,3.79)$ & $3.55(3.46,3.64)$ & 0.331 \\
\hline Short pamphlet & $2.98(2.83,3.13)$ & $3.60(3.52,3.68)$ & $<0.001$ \\
\hline \multicolumn{4}{|l|}{ Guideline presentation } \\
\hline Algorithms & $4.23(4.05,4.40)$ & $4.62(4.56,4.68)$ & $<0.001$ \\
\hline Point form & $4.17(4.01,4.33)$ & $4.56(4.50,4.62)$ & $<0.001$ \\
\hline Tables & $3.61(3.45,3.77)$ & $3.69(3.59,3.78)$ & 0.464 \\
\hline Graphs & $3.54(3.37,3.70)$ & $3.36(3.27,3.46)$ & 0.090 \\
\hline Combination of above choices & $4.17(4.00,4.33)$ & $4.09(4.00,4,18)$ & 0.469 \\
\hline Electronic format & $3.81(3.63,3.98)$ & $3.56(3.45,3.66)$ & 0.028 \\
\hline \multicolumn{4}{|l|}{ Electronic sources } \\
\hline Local ICU personal computer & $4.33(4.16,4.49)$ & $4.40(4.29,4.52)$ & 0.473 \\
\hline Hospital intranet & $4.00(3.74,4.26)$ & $4.47(4.37,4.57)$ & 0.001 \\
\hline Internet web site & $4.33(4.16,4.49)$ & $4.30(4.19,4.42)$ & 0.803 \\
\hline Computerized decision support & $3.38(3.11,3.64)$ & $3.18(3.03,3.32)$ & 0.194 \\
\hline CD Rom & $3.02(2.75,3.28)$ & $3.22(3.06,3.38)$ & 0.199 \\
\hline Palm pilot & $3.47(3.21,3.73)$ & $2.97(2.79,3.14)$ & 0.004 \\
\hline
\end{tabular}

Responses were framed on a continuous scale from $1=$ useless to $5=$ very useful for each question, where 3 is neutral. ICU $=$ intensive care unit; $\mathrm{CI}=$ confidence interval.

of nurses]. Nurses spent $21.7 \pm 7.8 \mathrm{yr}$ in clinical practice since graduation and practiced critical care for 6.9 \pm 8.0 yr. Most $(57.1 \%, 252 / 441)$ nurses worked as full time ICU clinicians. Physicians had been in practice $13.7 \pm 7.1$ years; $76.8 \%(93 / 121)$ spent more than half of their time in clinical practice and $53.7 \%(65 / 121)$ spent at least half of their clinical time in ICU.

\section{Informational resources used for patient care}

The majority of nurses $(70.2 \%, 301 / 429)$ and almost half of intensivists $(42.6 \%, 52 / 122)$ stated they use guidelines either frequently or always in practice $(P<$ $0.001)$ (Figure). Most $(92.5 \%, 516 / 558)$ respondents indicated they frequently or always use discussions with colleagues or consultants and multidisciplinary rounds to aid their clinical decision-making in the ICU. Significantly more nurses referred to colleagues $(P<0.001)$, multidisciplinary rounds $(P<0.001)$, and paper-based textbooks $(P=0.02)$ to inform patient care than did physicians. Physicians utilized original research articles $(P<0.001)$, systematic $(P<$ $0.001)$ and narrative $(P=0.001)$ reviews, and inter- 
TABLE IV Factors associated with stated guideline use

\begin{tabular}{llc}
\hline Predictor of increased guideline use for the corresponding respondent group & Physicians P-value & Nurses P-value \\
\hline $\begin{array}{l}\text { Respondent characteristics } \\
\text { Nurse respondents }\end{array}$ & N/A \\
$\begin{array}{l}\text { Greater time spent in clinical practice } \\
\text { Local factors }\end{array}$ & $P<005$ & $P<0.05$ \\
$\begin{array}{l}\text { Local guideline development committee } \\
\text { Guideline endorsement by a respected colleague }\end{array}$ & $P<0.01$ \\
$\begin{array}{l}\text { Beliefs } \\
\text { Belief that guidelines are motivated by desire to improve quality of care }\end{array}$ & $P<0.001$ & $P<0.001$ \\
$\begin{array}{l}\text { Belief that guidelines provide a convenient source of advice } \\
\text { Belief that guidelines are good educational tools }\end{array}$ & $P<0.05$ \\
\hline $\begin{array}{l}\text { Factors associated with a higher probability of stated guideline use. N/A }=\text { not applicable. } \mathrm{R}^{2} \text { (physicians regression) }=0.21, \mathrm{R}^{2} \text { (nurses } \\
\text { regression) }=0.06 .\end{array}$ &
\end{tabular}

TABLE V Stated barriers to guideline adherence

\begin{tabular}{llll}
\hline & $\begin{array}{l}\text { Physicians mean } \\
(95 \% \text { CI })\end{array}$ & $\begin{array}{l}\text { Nurses mean } \\
\text { (95\% CI) }\end{array}$ & $\begin{array}{l}\text { P-value for } \\
\text { mean difference }\end{array}$ \\
\hline Lack of agreement with guideline content & $3.93(3.78,4.09)$ & $3.59(3.48,3.70)$ & $<0.001$ \\
Lack of awareness about existence of guideline & $3.93(3.73,4.12)$ & $4.35(4.28,4.43)$ & $<0.001$ \\
Lack of familiarity with guideline content & $3.78(3.60,3.96)$ & $4.23(4.14,4.31)$ & $<0.001$ \\
Lack of familiarity with benefit associated with intervention(s) & $3.73(3.55,3.92)$ & $4.10(4.00,4.19)$ & $<0.001$ \\
described in guideline & & & \\
Lack of motivation to change & $2.60(2.38,2.82)$ & $3.04(2.91,3.17)$ & 0.002 \\
Perception of risk associated with guideline implementation & $3.54(3.35,3.73)$ & $3.93(3.83,4.03)$ & $<0.001$ \\
Your lack of access to guideline & $3.34(3.13,3.54)$ & $4.10(4.00,4.20)$ & $<0.001$ \\
Lack of formal implementation strategies at your institution & $3.57(3.36,3.77)$ & $4.08(3.99,4.18)$ & $<0.001$ \\
Lack of institutional prioritization for guidelines & $3.61(3.40,3.81)$ & $4.05(3.95,4.14)$ & $<0.001$ \\
Your lack of time & $3.35(3.12,3.58)$ & $3.87(3.76,3.97)$ & $<0.001$ \\
\hline
\end{tabular}

Responses were framed on a continuous scale from $1=$ unimportant to $5=$ very important for each question, where 3 is neutral. CI $=$ confidence interval.

net-based textbooks $(P=0.006)$ to a greater extent than nurses.

\section{Guideline development}

Most respondents stated that their ICUs develop their own practice guidelines $[85.1 \%(103 / 121)$ of physicians, $79.6 \%(344 / 432)$ of nurses]. Slightly fewer than half $(262 / 548)$ stated they had a formal guideline development committee, but $62.3 \%(340 / 546)$ reported that a local expert or practice leader was responsible for guideline development. Professional society guidelines (with or without local modification) were reportedly used by $65.3 \%(358 / 548)$ of respondents. More than half of the nurses were confident about the validity of both Canadian and American Associations of Critical Care Nurses guidelines; nurses were more confident than physicians $(P<0.001)$. At least half of physicians were confident in guidelines produced by professional societies. They were more confident than nurses $(P<0.001)$, about the validity of guidelines developed jointly by the Canadian
Critical Care Society and the Canadian Critical Care Trials Group, American College of Chest Physicians, American Thoracic Society, Society of Critical Care Medicine, and European Society of Intensive Care Medicine. Physicians were more confident about the validity of locally developed guidelines than were nurses $(P<0.001)$. Both groups were uncertain about the validity of guidelines developed by industry or nonprofessional societies; nurses were more uncertain than physicians about industry guidelines $(P<0.001)$.

\section{Attitudes towards guidelines and their format}

Both groups viewed guidelines as educational tools, and perceived that their development is motivated primarily by the desire to improve quality of care. Neither group believed that guidelines are oversimplified, too rigid to apply to individual patients, or that they challenge clinician autonomy (Table II). Guideline simplicity was important to both physicians and nurses when considering guideline adoption. Physicians considered endorsement of a guideline by 
a colleague more relevant to guideline uptake than did nurses, $(P<0.001)$, but nurses considered low risk of the guideline and whether the guideline is consistent with their practice more relevant than did physicians $(P<0.001$ for both $)$.

Format and presentation preferences differed significantly between physicians and nurses (Table III). Pre-printed orders were the paper format most preferred by both groups. Both reported that journal articles about guidelines and structured summaries of research underpinning the guidelines are relatively unhelpful. Neither group found that pocket cards, posters, or short pamphlets were particularly useful; nonetheless, were deemed more useful by nurses than by physicians $(P<0.001)$. Algorithms were the most preferred format for guidelines, favoured more by nurses than physicians $(P<0.001)$. Both groups stated that a combination of formats was useful. Almost $2 / 3(317 / 545)$ of clinicians stated that electronic formats were somewhat or very useful, $59.7 \%$ $(316 / 529)$ of clinicians [60.0\% $(249 / 415)$ of nurses, $58.8 \%(67 / 114)$ of physicians] stated that they use electronic methods to access guidelines in the ICU. Nurses and physicians considered local ICU computers, hospital intranets, and Internet web sites most useful to access guidelines.

\section{Factors associated with and barriers to guideline use} Table IV illustrates the factors independently associated with nurses' and physicians' self-reported use of guidelines; determined from regression analyses. Physicians reported lack of agreement with recommendations and lack of awareness of guidelines as the most important barriers to use of guidelines (Table V). Nurses reported that lack of awareness of the guideline, lack of familiarity with the guideline content, and lack of familiarity with the benefit of the interventions, were important barriers to use of guidelines. Nurses perceived all barriers as more important determinants of use of guidelines than did physicians.

\section{Discussion}

This national survey found that most Canadian ICU clinicians use guidelines in practice. Most ICUs have a local expert or practice leader responsible for guideline development, rather than a formal guideline development committee. Most guidelines in use were described as locally developed. All clinicians prefer simple formats such as pre-printed orders, and simple presentation such as algorithms. Most respondents stated that they use electronic methods to access guidelines in their ICUs. Almost half stated that they find electronic sources to be very useful; local ICU computers and Internet web sites are of greatest utility to both groups. Clinicians did not regard guidelines as oversimplified or too rigid to apply to individual patients. Neither nurses nor physicians believe that guidelines challenge clinician autonomy, or that disciplinary action would result if guidelines are not followed.

We found important differences between nurses' and physicians' attitudes towards guidelines. Nurses reported more frequent use of guidelines. Physicians considered endorsement of guidelines by a colleague to be more relevant than did nurses, while nurses considered the perceived guideline risk as more relevant to guideline uptake than did physicians. Guideline format and presentation preferences also differed; nurses prefer short pamphlets, pocket cards, posters, and manuals. Interestingly, physicians participating in our survey do not place high importance on barriers, particularly in relation to nurses; that finding contrasts with those of Cabana et al. ${ }^{13} \mathrm{~A}$ better understanding of clinicians' perceptions of barriers to guideline adherence may be used to address these barriers directly to improve guideline adherence.

There are interesting differences when comparing our results to those of internists surveyed between 1993 and 1997. ${ }^{10-12}$ Canadian and US internists previously reported that using guidelines makes practice less satisfying; guidelines were perceived as providing an oversimplified approach to medicine, being too rigid to apply to individual patients, and that they challenge physician autonomy. ${ }^{10-12}$ By contrast, we found that ICU clinicians neither regard guidelines as oversimplifications nor as threats to their autonomy. The reported utility of guidelines in the ICU today may reflect their longstanding availability across the spectrum of in-patient and out-patient practice. Intensive care unit clinicians pressured by the burgeoning medical literature and increasing demands may find evidence-based practice guidelines more useful today.

We found that few clinicians reported using original research articles, narrative or systematic reviews, or other literature such as textbooks to inform clinical decision-making. This underscores the need for instruments such as guidelines that synthesize the evidence for clinical use at the bedside. Guidelines may be welcome tools in the complex, technologydependent ICU environment, because they are based on a synthesis of the best available evidence, can help standardize patient care, and can help avoid errors of omission. The large number of ICU-specific guidelines and their frequent use in practice, as reported by our respondents, support this notion. Nevertheless, 


\section{Appendix}

TABLE Independent variables included univariable analysis of linear regression

\begin{tabular}{|c|c|c|}
\hline \multirow[t]{2}{*}{ Independent variables considered } & \multicolumn{2}{|c|}{ Linear regression model } \\
\hline & Intensivists only & Nurses only \\
\hline \multicolumn{3}{|l|}{ Demographic } \\
\hline Years of critical care practice & * & * \\
\hline Community vs university affiliation & * & * \\
\hline \multicolumn{3}{|l|}{ Intensivist vs nurse } \\
\hline Percent time spent in clinical practice & * & * 1 \\
\hline \multicolumn{3}{|l|}{ Guideline development } \\
\hline Local guideline development committee that may include a local expert & * & * \\
\hline Organization developing the guideline & * & * \\
\hline \multicolumn{3}{|l|}{ Attitudes towards guidelines } \\
\hline Desire to improve quality of patient care & * & * \\
\hline Desire to cut costs & & * \\
\hline \multicolumn{3}{|l|}{ Convenient source of advice } \\
\hline Good educational tools & * & * \\
\hline \multicolumn{3}{|l|}{ Guidelines are either oversimplified or too rigid } \\
\hline \multicolumn{3}{|l|}{ Disciplinary action if guidelines not followed } \\
\hline \multicolumn{3}{|l|}{ Guideline qualities } \\
\hline Guideline simplicity & & * \\
\hline Consistency with local practice & * & * \\
\hline Guideline endorsed by respected colleague & & * \\
\hline \multicolumn{3}{|l|}{ Guideline implementation } \\
\hline Time to implement guideline & & * \\
\hline CD ROM format of guideline & & * \\
\hline \multicolumn{3}{|l|}{ Barriers to guideline adherence } \\
\hline \multicolumn{3}{|l|}{ Lack of agreement with guideline content } \\
\hline \multicolumn{3}{|l|}{ Lack of personal motivation to change behaviour } \\
\hline \multicolumn{3}{|l|}{ Lack of formal institutional implementation strategies } \\
\hline $\begin{array}{l}\text { The independent variable included in the univariable analyses for the diff } \\
\text { independent variables for inclusion in the models were based on a priori } 1 \\
\text { respondents. } \\
{ }^{1} \text { This variable was coded as clinical (full or part time) vs other (clinical pa } \\
\text { role) }\end{array}$ & $\begin{array}{l}\text { sion models is d } \\
\text { ithin acceptable } 1 \\
\text { or educator or }\end{array}$ & $\begin{array}{l}\text { symbol. The } \\
\text { nple size of } \\
\text { er non-clinical }\end{array}$ \\
\hline
\end{tabular}

several crucial issues remain, including the need for transparency in how recommendations are adduced, 18 full disclosure of conflicts of interest in their development ${ }^{19}$ and dissemination, ${ }^{20}$ and the need to evaluate whether guidelines have unintended negative consequences. $^{21}$

Our study has several limitations. First, the overall response rate to our survey was $51.6 \%$; our results may not represent the attitudes of non-responding physicians and nurses. Second, our sample frame was limited to members of the CCCS and CACCN; most of these clinicians were university-affiliated. We did not survey other ICU team members exposed to guidelines, including pharmacists, respiratory therapists, or residents in the ICU, whose views may differ from nurses and intensivists. Third, it is plausible that the stated differences in attitudes between physicians and nurses represent a tendency of nurses to respond more affirmatively to survey questions than physicians. Fourth, it is also possible that perceived differences between nurses and physicians in the value of guidelines and barriers to their use reflect a tendency of nurses to refer specifically to nursing guidelines rather than to general clinical or medical guidelines. ${ }^{22}$ While we found statistically significant differences between physicians and nurses, the nature and extent of these differences in practice and their influence on clinician adherence to guidelines in the ICU remains uncertain. Finally, respondents may have interpreted the definitions of guidelines, protocols, clinical pathways, and algorithms we provided differently. Considering the limitations of self-administered survey methods to delineate nuances, enriched understanding of these issues could be obtained through qualitative research.

Our study has several strengths. First, we used a rigorous approach to questionnaire development and 
testing ${ }^{23-25}$ to optimize the internal validity of our instrument. ${ }^{26}$ Second, to maximize the generalizability of our results, we conducted a national survey. Third, we included ICU nurses in our sample because as key members of the multidisciplinary team spending the most time directly with patients, nurses are integral to optimal patient care, and fundamental to guideline uptake. Fourth, we included a broad range of questions to elucidate key attitudes towards guidelines, and used regression analysis to describe predictors of guideline use. Finally, we extended data published on views of pediatric intensivists ${ }^{27}$ by comprehensively examining the attitudes and preferences of adult intensivists and ICU nurses regarding guidelines.

Intensive care unit clinicians in Canada report using guidelines with the view that they are convenient sources of advice primarily developed to improve quality of care. Differences between physicians and nurses in their attitudes towards the utility of guidelines, their preferences regarding format and presentation, and their views on barriers, may differentially influence guideline uptake between these clinician groups. Modifying guideline development and implementation strategies to address these barriers and capitalize on these preferences may improve use of guidelines in the ICU. Suggestions from this study include creating pre-printed orders, simplifying guideline formats, ensuring computer access to guideline repository websites, and communicating about guidelines on the hospital intranet.

\section{References}

I Pilon CS, Leathley M, London R, et al. Practice guideline for arterial blood gas measurement in the intensive care unit decreases numbers and increases appropriateness of tests. Crit Care Med 1997; 25: 1308-13.

2 Pitimana-aree S, Forrest D, Brown G, Anis A Wang $X H$ Dodek $\mathrm{Pl}$. Implementation of a clinical practice guideline for stress ulcer prophylaxis increases appropriateness and decreases cost of care. Intensive Care Med 1998; 24: 217-23.

3 McMullin J, Cook D, Griffith L, et al. Minimizing errors of omission: behavioural reenforcement of heparin to avert venous emboli: the BEHAVE study. Crit Care Med 2006; 34: 694-9.

4 Baxter AD, Allan J, Bedard J, et al. Adherence to simple and effective measure reduces the incidence of ventilator-associated pneumonia. Can J Anesth 2005; 52: $535-41$.

5 Mascia MF, Koch M, Medicis JJ. Pharmacoeconomic impact of rational use guidelines on the provision of analgesia, sedation, and neuromuscular blockade in critical care. Crit Care Med 2000; 28: 2300-6.
6 Brattebo G, Hofoss D, Flaatten H, Muri AK, Gjerde S, Plsek PE. Effect of a scoring system and protocol for sedation on duration of patients' need for ventilator support in a surgical intensive care unit. BMJ 2002; 324: 1386-9.

7 Merlani P, Garnerin P, Diby M, Ferring M, Ricou B. Quality improvement report: linking guideline to regular feedback to increase appropriate requests for clinical tests: blood gas analysis in intensive care. BMJ 2001; 323: 620-4.

8 Jain MK, Heyland DK, Dhaliwal R, et al. Dissemination of the Canadian clinical practice guidelines for nutrition support: results of a cluster randomized controlled trial. Crit Care Med 2006; 34: 2362-9.

9 Dodek P, Keenan S, Cook D, et al.; Canadian Critical Car Trials Group; Canadian Critical Care Society. Evidence-based clinical practice guideline for the prevention of ventilator-associated pneumonia. Ann Intern Med 2004; 141: 305-13.

10 Hayward RS, Guyatt GH, Moore KA, McKibbon KA, Carter $A O$. Canadian physicians' attitudes about and preferences regarding clinical practice guidelines. CMAJ 1997; 156: 1715-23.

11 Hayward RS, Wilson MC, Tunis SR, Guyatt GH, Moore $K A$, Bass EB. Practice guidelines. What are we looking for? J Gen Intern Med 1996; 11: 176-8.

12 Tunis SR, Hayward RS, Wilson MC, et al. Internists' attitudes about clinical practice guidelines. Ann Intern Med 1994; 120: 956-63.

13 Cabana MD, Rand CS, Powe NR, et al. Why don't physicians follow clinical practice guidelines? A framework for improvement. JAMA 1999; 282: 1458-65.

14 Sinuff T, Kahnamoui K, Cook DJ, Giacomini M. Practice guidelines as multipurpose tools: a qualitative study of noninvasive ventilation. Crit Care Med 2007; 35: 776-82.

15 Cook DJ, Meade MO, Hand LE, McMullin JP. Toward understanding evidence uptake: Semirecumbency for pneumonia prevention. Crit Care Med 2002; 30: $1472-7$.

16 Fleiss JL, Cohen J. The equivalence of weighted kappa and the intraclass correlation coefficient as measures of reliability. Educational and Psychological Measurement 1973; 33: 613-9.

17 Kleinbaum DG, Kupper LL, Muller KE, Nizam A. Applied regression analysis and other multivariable methods. Toronto, Duxbury Press; 1998: 118-85.

18 Atkins D, Best D, Briss PA, et al.; GRADE Working Group. Grading quality of evidence and strength of recommendations. BMJ 2004; 328: 1490.

19 Choudhry NK, Stelfox HT, Detsky AS. Relationships between authors of clinical practice guidelines and the 
pharmaceutical industry. JAMA 2002; 87: 612-7.

20 Eichacker PQ Natanson C, Danner RL. Surviving sepsis - practice guidelines, marketing campaigns, and Eli Lilly. N Engl J Med 2006; 355: 1640-2.

21 Wachter RM. Expected and unanticipated consequences of the quality and information technology revolutions. JAMA 2006; 295: 2780-3.

22 Streiner DL, Norman GR. Biases in Responding, Health Measurement Scales. New York, Oxford University Press; 2003: 80-101.

23 Feinstein AR, Josephy BR, Wells CK. Scientific and clinical problems in indexes of functional disability. Ann Intern Med 1986; 105: 413-20.

24 Feinstein AR, Wells CK, Joyce CM, Josephy BR. The evaluation of sensibility and the role of patient collaboration in clinimetric indexes. Trans Assoc Am Physicians 1985; 98: 146-9.

25 Cook DJ, Guyatt GH, Jaeschke R, et al. Determinants in Canadian health care workers of the decision to withdraw life support from the critically ill. Canadian Critical Care Trials Group. JAMA 1995; 273: 703-8.

26 Aday LA. Designing and Conducting Health Surveys. San Francisco, Jossey Bass Publishers; 1989.
27 Zucker AR, Meadow WL. Pediatric critical care physicians' attitudes about guidelines for the use of ribavirin in critically ill children with respiratory syncytial virus pneumonia. Crit Care Med 1995; 23: 767-72.

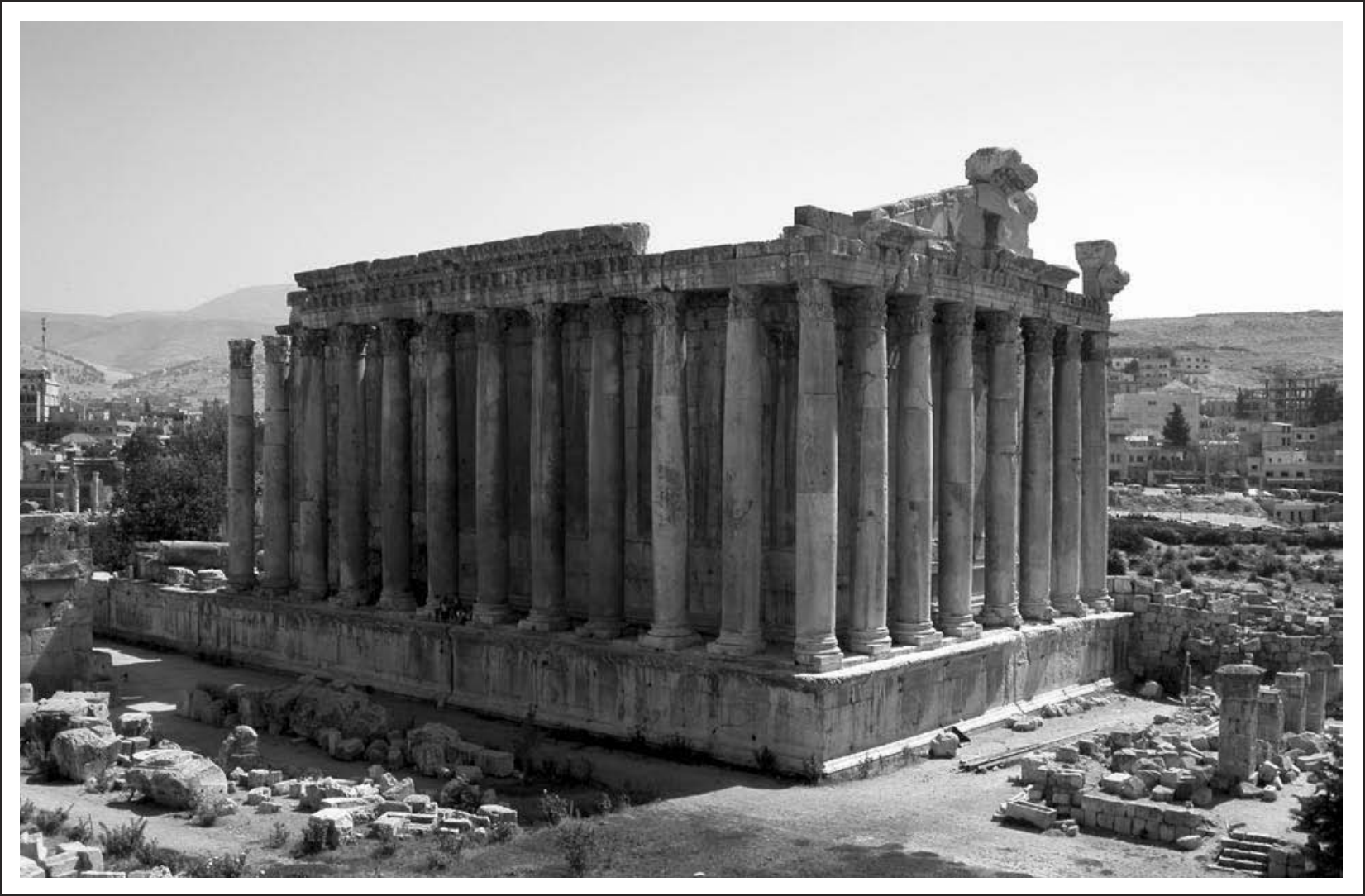

Baalbeck - Lebanon 